\title{
ANALISIS KINERJA RANTAI PASOK DENGAN SUPPLY CHAIN OPERATION RESEARCH DAN ANALYTICAL HIERARCHY PROCESS (STUDI KASUS UMKM TEMPO SUSU MALANG)
}

\author{
Qurrotul Aini ${ }^{1)}$, Adli Muhammad Putra Pratama ${ }^{2)}$, dan Farah Dhia Yasmin ${ }^{3)}$ \\ ${ }^{1,2,3}$ Program Studi Sistem Informasi, Fakultas Sains dan Teknologi, Universitas Islam Negeri Syarif Hidayatullah \\ $1,2,3$ Jl. Ir. H. Juanda No. 95 Ciputat, Tangerang Selatan, 15412 \\ E-mail : qurrotul.aini@uinjkt.ac.id ${ }^{1)}$, adli.muhammad16@mhs.uinjkt.ac.id ${ }^{2)}$,farah.dhia16@mhs.uinjkt.ac.id ${ }^{3)}$
}

\begin{abstract}
ABSTRAK
Perusahaan yang berkeinginan untuk meningkatkan daya saing harus memperhatikan kinerja rantai pasok yang dimiliki. Pengukuran kinerja rantai pasok diperlukan untuk memperbaiki parameter kinerja tertentu. Usaha mikro, kecil dan menengah (UMKM) Tempo Susu yang berkeinginan melakukan ekspansi bisnis namun terkendala dengan kapasitasnya yang belum memadai, sehingga diperlukan pengukuran kinerja rantai pasok dengan menggunakan Supply Chain Operation Reference (SCOR) dan Analytical Hierarchy Process (AHP). Pengukuran dilakukan dengan menyesuaikan proses bisnis dan rantai pasok perusahaan pada metrik level 1 sampai 3 pada model SCOR. Selanjutnya, hasil pengukuran dinormalisasi menggunakan Snorm de Boer. Pembobotan dilakukan pada performance attributes menggunakan AHP dengan membandingkan setiap performance attributes dan proses yang terjadi di dalamnya. Nilai akhir pengukuran kinerja yang diperoleh reliability 10,5 ; responsiveness 7,5 ; agility 7,71 ; cost 12,21 ; dan manajemen aset 20,63. Total nilai kinerja sebesar 58,55 yang tergolong rata-rata. UMKM Tempo Susu disarankan untuk memperbaiki kinerjanya pada performance atributes yaitu responsiveness berupa respon waktu dalam memenuhi pesanan yang meliputi mendapatkan bahan baku, pembuatan dan pengiriman produk.
\end{abstract}

Kata Kunci: Rantai Pasok, Supply Chain Operation Research, Supply Chain Management, Analytical Hierarchy Process, Usaha mikro, kecil, dan menengah.

\section{PENDAHULUAN}

Supply Chain Management (SCM) merupakan salah satu faktor penting dalam perusahaan yang bisa meningkatkan daya saing dan keuntungan pada suatu perusahaan. Ada enam drivers yang berperan penting menentukan jalannya manajemen rantai pasok yaitu, fasilitas, inventaris, transportasi, informasi, penentuan harga, dan penentuan sumber (Chopra \& Meindl, 2016). Keenam drivers inilah yang akan dilihat pada Tempo Susu dengan cara mengukur kinerja dari rantai pasoknya. Tempo Susu adalah usaha mikro, kecil, dan menengah (UMKM) yang didirikan oleh sekelompok mahasiswa yang berasal dari Universitas Brawijaya pada tahun 2018. UMKM ini memproduksi susu pasteurisasi dengan varian rasa coklat dan original. Produk susu ini memiliki pangsa pasar kaum muda. Tempo Susu ingin membangkitkan kesadaran kaum muda akan hidup sehat dengan mengonsumsi susu.

UMKM Tempo Susu berencana melakukan ekspansi dagangnya. Namun, ada beberapa kendala dalam proses tersebut khususnya dalam rantai pasokannya. Kendalanya adalah kurangnya produktivitas sehingga kapasitas produk belum memadai untuk dilakukannya ekspansi. UMKM Tempo Susu selama ini baru mampu melakukan produksi maksimal 100 botol dalam satu pekan. Sedangkan, dibutuhkan setidaknya 400 botol dalam sepekan jika ingin melakukan ekspansi. Oleh karena itu, diperlukan pengukuran kinerja dari setiap tahapan dalam rantai pasok Tempo Susu. Pengukuran ini bertujuan untuk mengetahui atribut kinerja yang paling berpengaruh dan atribut kinerja yang kinerjanya masih harus diperbaiki dalam rantai pasokan Tempo Susu.

Seperti yang dilakukan pada penelitian sebelumya, pengukuran kinerja rantai pasokan yang telah dilakukan dengan beberapa atribut, dan hasil kinerjanya masih harus diperbaiki dan belum mencapai nilai yang mencukupi menurut model SCOR (Mutakin \& Hubeis, 2011). Penelitian lain mengombinasikan model SCOR dengan Fuzzy-AHP mendapatkan hasil berupa nilai bobot untuk masing-masing metrik (Setiawan dkk, 2010). Dan terdapat penelitian yang juga menerapkan model SCOR dan AHP menghasilkan nilai pengukuran performa dan menentukan proses supply chain yang menjadi prioritas bagi perusahaan (Luthfiana \& Perdana, 2001).

Penulis mengusulkan untuk melakukan pengukuran kinerja rantai pasok pada Tempo Susu dengan menggunakan model SCOR dan AHP. Model SCOR ini dapat disesuaikan dengan perusahaan untuk mengukur kinerja rantai pasok dengan menilai metrik yang terbagi ke dalam tiga level. Kemudian dilakukan pembobotan metrik menggunakan AHP. Kontribusi dari penelitian ini adalah penentuan atribut kinerja (performance attributes) yaitu responsiveness yang perlu ditingkatkan dalam kecepatan memenuhi pesanan hingga pengiriman 
ke pelanggan khususnya untuk UMKM sebagai studi kasus.

\section{RUANG LINGKUP}

Dalam penelitian ini permasalahan mencakup proses bisnis yang melibatkan pasokan dari beberapa bahan mentah untuk membuat produk di Tempo Susu Malang. Sedangkan performance perhitungan atribut kinerja meliputi: reliability, responsiveness, agility, cost, dan manajemen aset. Adapun rencana yang dihadilkan dapat digunakan untuk memperbaiki performance Tempo Susu dan dapat melakukan ekspansi atau varian terhadap produknya.

\section{BAHAN DAN METODE}

Bahan penelitian adalah pustaka yang mendukung dan dijelaskan dalam sub bab berikut. Sedangkan metode penelitian mencakup langkah analisis kinerja rantai pasok hingga mendapatkan hasil yang diinginkan.

\subsection{Pengukuran Kinerja}

Bahan terdiri dari 1-3 teori yang utama mendukung penelitian yang dilakukan, teori yang relevan dengan penelitian dan harus mengacu pada daftar pustaka (last name, year). Pengukuran (measurement) adalah proses pengumpulan data secara empiris untuk mendapatkan dan menjadi informasi yang relevan dengan tujuan tertentu. Dua karakteristik utama pengukuran yaitu: penggunaan atau skala tertentu dan memiliki suatu aturan atau formula. Pengukuran bisa juga berarti pemberian suatu nilai angka kepada suatu atribut atau karakter dengan mengikuti aturan tertentu (Cangelosi, 1995). Pengukuran bisa dimaksudkan juga sejumlah data yang dikumpul dengan menggunakan alat ukur yang objektif untuk keperluan analisis (Rakhman, 2010). Sedangkan kinerja adalah gambaran tentang tingkat pencapaian suatu program yang sudah dilaksanakan dalam mewujudkan visi, misi, dan sasaran sesuai perencanaan strategi suatu organisasi disebut dengan kinerja (Moehriono, 2012).

\subsection{Rantai Pasok}

Rantai pasok merupakan rangkaian aliran barang/fisik, informasi dan proses yang digunakan untuk mengirim produk atau jasa dari lokasi sumber (pemasok) ke lokasi tujuan (pelanggan atau pembeli). Dengan kata lain rantai pasok adalah serangkaian cara pendekatan yang digunakan untuk mengintegrasikan pemasok, produsen, gudang dan toko sehingga barang yang dihasilkan dan didistribusikan ada pada jumlah dan waktu yang tepat untuk meminimalisasi biaya (Mutakin \& Hubeis, 2011).

\subsection{Supply Chain Operation Research}

Model SCOR merupakan model yang digunakan sebagai alat untuk mengukur kinerja rantai pasok sebuah perusahaan dan mengkomunikasikan pada pihak-pihak yang terlibat di dalamnya. SCOR yang dikembangkan oleh Supply Chain Council ini menghubungkan performa metrik, proses, best-practices, dan manusia ke dalam suatu struktur. SCOR membagi bagian performa menjadi dua bagian; performance attributes dan metrik. Performances attributes terbagi menjadi lima, yaitu: (Supply Chain Council, 2012; Wahyuniardi \& Pasundan, 2017)

1. Reliability: kemampuan untuk mengerjakan tugas sesuai yang diharapkan

2. Responsiveness: kecepatan menyelesaikan tugas.

3. Agility: kemampuan untuk merespon pengaruh dari luar, perubahan marketplace untuk mengelola keunggulan kompetitif

4. Cost: biaya operasi proses rantai pasok

5. Asset Management Efficiency: kemampuan untuk memanfaatkan aset dengan efisien.

Dalam performance attributes terdapat metrik-metrik yang terbagi menjadi tiga level:

1. Level 1 adalah ukuran keseluruhan rantai pasok yang dapat membantu menetapkan target realistis untuk tujuan bisnis. Metrik pada level 1 juga disebut dengan key performance indicator (KPI).

2. Level 2 merupakan ukuran untuk mengukur penyebab kesenjangan yang ada pada metrik level 1.

3. Level 3 merupakan ukuran untuk mengukur metrik level 2. Metrik-metrik tiap level dapat disesuaikan dengan proses yang berjalan pada perusahaan (Setiawan dkk, 2010).

\subsection{Proses Normalisasi}

Normalisasi dilakukan untuk menyamakan nilai hasil perhitungan metrik. Dalam perhitungannya, metrikmetrik performance attributes mempunyai skala ukuran yang berbeda. Proses normalisasi ini dilakukan dengan rumus normalisasi Snorm De Boer (Wigaringtyas, 2013), yaitu:

$$
\frac{\left(S_{i}-S_{\min }\right)}{\left(S_{\max }-S_{\min }\right)}=\frac{s k o r-0}{100-0}
$$

dengan $S_{i}(1)$ adalah nilai indikator aktual yang berhasil dicapai dan $S_{\text {min }}$ adalah nilai pencapaian performansi terburuk dari indikator kinerja. $S_{\mathbf{m a x}}$ adalah nilai pencapaian performansi terbaik dari indikator kinerja.

Setiap proses normalisasi menghasilkan skor yang mempunyai interval 0 sampai 100 , sehingga parameter dari setiap perhitungan metriks akan sama untuk dilakukan pengukkuran indikator kinerjanya. Berikut Tabel 1 menunjukkan sistem monitoring indikator kinerja. 
Tabel 1. Sistem Monitoring Indikator Kinerja

\begin{tabular}{cc}
\hline Sistem Monitoring & Indikator Kinerja \\
\hline$<40$ & Poor \\
$40-50$ & Marginal \\
$50-70$ & Average \\
$70-90$ & Good \\
\hline$>90$ & Excellent \\
\hline
\end{tabular}

\subsection{Analytical Hierarchy Process}

AHP adalah sebuah metode penyelesaian permasalahan yang komplek dalam situasi yang tidak terstruktur menjadi bagian-bagian komponen. Prinsip dasar AHP adalah menyusun hierarki, penilaian kriteria dan alternatif, synthesis of priority (menentukan prioritas), dan konsistensi logis (Pranoto, Muslim, \& Hasanah, 2013; Ukkas, Yusnita, \& Wandana, 2013; Palupi, Lailiyah, \& Sihotang, 2014).

Prosedur yang perlu dilakukan dalam AHP adalah:

1. Mendefinisikan masalah dan menentukan solusi yang diinginkan, lalu menyusun hirarki dari permasalahan yang dihadapi. Penyusunan hirarki adalah dengan menetapkan tujuan yang merupakan sasaran sistem secara keseluruhan pada level teratas.

2. Menentukan prioritas elemen. Langkah pertama dalam menentukan prioritas elemen adalah membuat perbandingan berpasangan, yaitu membandingkan elemen secara berpasangan sesuai kriteria yang diberikan. Metriks perbandingan berpasangan diisi menggunakan bilangan untuk merepresentasikan kepentingan relatif dari suatu elemen terhadap elemen lainnya.

3. Mensintesis pertimbangan-pertimbangan terhadap perbandingan berpasangan untuk memperoleh keseluruhan prioritas.

4. Mengukur Konsistensi dengan cara kalikan setiap nilai pada kolom pertama dengan prioritas relatif elemen pertama, nilai pada kolom kedua dengan prioritas relatif elemen kedua dan seterusnya. Lalu jumlahkan setiap baris Hasil dari penjumlahan baris dibagi dengan elemen prioritas relatif yang bersangkutan. Menjumlahkan hasil bagi di atas dengan banyaknya elemen yang ada. Hasilnya disebut $\lambda$ maksimal.

5. Menghitung Consistency Index (CI) dengan persamaan:

$$
C I=\frac{\left(\lambda_{\max }-n\right)}{n}
$$

dengan $n$ pada pers. (2) adalah banyaknya elemen.

6. Menghitung rasio konsistensi atau consistency ratio $(C R)$ dengan persamaan:

$$
C R=\frac{C I}{I R}
$$

dengan CI (3) merupakan consistency index atau indeks konsistensi dan IR index random consistency atau konsistensi acak indeks. Jika $C R$ yang didapat kurang dari sama dengan 0,1 maka hasil perhitungan dapat dinyatakan benar (Pranoto, Muslim, \& Hasanah, 2013).

\subsection{Penelitian Sejenis}

Penelitian sebelumnya mengenai pengukuran kinerja pada PT Indocement Tunggal Prakarsa (ITP) dengan SCOR model 9.0 menggunakan data kuantitatif dan kualitatif. Metrik-metrik yang digunakan pada penelitian ini adalah kehandalan rantai pasokan, tingkat respons rantai pasokan, biaya rantai pasokan, dan manajemen aset rantai pasokan. Hasil pengukuran menunjukkan bahwa SCM yang diterapkan pada perusahaan tersebut sudah baik dengan menerapkan lima proses ini secara terintegrasi. Namun masih kurang memperhatikan proses pengiriman. Setiap langkah penelitian dijelaskan secara detail serta dilengkapi dengan bagan dan diagram yang memudahkan pembaca untuk memahami penelitian (Mutakin \& Hubeis, 2011).

Penelitian lain pada PT. Indofarma Global Media (IGM) juga menggunakan metode SCOR dan AHP. Tools yang digunakan adalah SCOR 8.0 dengan hasil perfect order fulfillment adalah $100 \%$, order fulfillment cycle time adalah 2 hari, deliver cycle time adalah 30 hari, supply chain flexibility and adaptabilitya dalah $72 \%$, dan cash to cash cycle time dengan waktu 30 hari. Performance attributes yang diprioritaskan PT. IGM adalah supply chain asset management (Setiawan dkk, 2010).

Selain itu terdapat pula penelitian yang menggunakan green SCOR model untuk mengukur kinerja dengan menggunakan 16 metrik yang berkaitan dengan lingkungan pada suatu perusahaan. Penelitian ini menggunakan studi literatur, studi lapangan serta metode AHP. Hasil penelitian menunjukkan bahwa nilai skor 60,13 yang termasuk dalam kategori good performance sesuai dengan ketetapan perusahaan sebelumnya. Akan tetapi nilai ini berada di ambang batas kategori yang baik dan kategori yang buruk (Natalia \& Astuario, 2015).

Adapun penelitian pada UD. Maju Jaya yang menggunakan metode kualitatif kemudian dengan metode pengambilan data snowball sampling dan diolah dengan metode deskriptif yang memiliki metrik waktu produk dari produsen sampai ke pelanggan, biaya yang dibutuhkan, perbedaan biaya dengan di pasar, dan proses rantai pasok. Penelitian menunjukkan bahwa estimasi total waktu yang diperlukan untuk sampai ke pengguna akhir adalah 32 hari (Budiman, 2013).

\subsection{Metode Penelitian}

Penelitian ini menggunakan metode kualitatif dengan mengambil data primer dari hasil observasi dan wawancara serta data pendukung didapat dari studi literatur artikel jurnal terkait. Pengukuran kinerja dilakukan dengan menggunakan SCOR. Di dalam rantai pasok terdapat lima performance attributes yang mempengaruhi kinerja dari proses-proses dalam rantai pasok yaitu, deliverable, responsiveness, agility, cost, dan assets management efficiency. Metrik dari setiap 
atribut ditentukan berdasarkan proses bisnis dan rantai pasok yang ada. Setelah ditentukan, setiap metrik dinilai berdasarkan kinerja yang sebenarnya. Hasil dari penilaian dinormalisasi untuk standarisasi penilaian. Hasil normalisasi akan dikali dengan hasil pembobotan dari proses AHP. Dari nilai akhir, dapat ditentukan nilai kinerja di masing-masing performance attributes rantai pasok pada UMKM Tempo Susu, Malang. Berikut tahapan-tahapan penelitian:

1. Tahap awal penelitian dengan melakukan studi pustaka dan lapangan berupa wawancara dengan cofounder Tempo Susu untuk mengidentifikasi masalah yang ada dan tujuan penelitian.

2. Tahap pengumpulan data kualitatif, meliputi proses bisnis dan rantai pasok pada Tempo Susu dengan mewawancarai co-founder Tempo Susu yang memahami rantai pasok pada perusahaan tersebut. selain itu juga dikumpulkan data-data pendukung yang didapatkan dengan cara studi literatur jurnal sejenis, buku panduan SCOR, dan artikel terkait dari internet.

3. Klasifikasi pemetaan rantai pasok pada Model SCOR yang didapatkan dengan cara wawancara dan brainstorming dengan pihak Tempo Susu. Klasifikasi dilakukan untuk menentukan metrik-metrik pada masing-masing level 1 , level 2 dan level 3 berdasarkan proses bisnis dan rantai pasok yang terjadi pada Tempo Susu (Wahyuniardi \& Pasundan, 2017).

4. Pengumpulan data kuantitatif yang digunakan untuk perhitungan metrik yang telah ditentukan sebelumnya. Data kuantitatif didapat dari hasil wawancara dengan co-founder Tempo Susu.

5. Perhitungan nilai aktual metrik pada hierarki SCOR pengukuran kinerja harus menggunakan persamaan yang dapat dilihat pada pustaka SCOR versi 11.0. Perhitungan dilakukan dengan cara bottom-up. Perhitungan dimulai dari level 3 yang kemudian diakumulasi yang akan menjadi nilai dari level 2 .
Kemudian kumpulan metrik di level 2 diakumulasi yang akan menjadi nilai dari metrik level 1.

6. Normalisasi metrik dilakukan ketika nilai hasil perhitungan metrik level 1 mempunyai skala nilai yang berbeda. Oleh karena itu perlu dilakukan penyamaan skala nilai tersebut. Normalisasi akan menghasilkan nilai skor yang dikonversikan ke dalam konversi nilai tertentu yaitu antara 0 sampai 100 .

7. Pembobotan metrik level 1 dilakukan dengan metode AHP. Pembobotan ini dilakukan untuk mengetahui tingkat kepentingan performance attributes UMKM Tempo Susu.

8. Menghitung nilai akhir kinerja rantai pasok. Nilai akhir kinerja rantai pasok didapat dari hasil perkalian normalisasi (skor) dengan hasil pembobotan AHP (bobot). Nilai akhir ini dapat menentukan tingkat kinerja rantai pasok.

\section{PEMBAHASAN}

Pada bagian ini dijelaskan proses bisnis dan rantai pasok Tempo Susu Malang, klasifikasi pemetaan rantai pasok, serta perhitungan nilai SCOR dan pembobotan AHP.

\subsection{Proses Bisnis dan Rantai Pasok Tempo Susu}

Proses bisnis dan Rantai Pasok didapat dari hasil wawancara dengan co-founder Tempo Susu. Proses bisnis dan rantai pasok ditunjukkan pada Gambar 1. Sebelum memulai produksi susu, Tempo Susu menghubungi supplier susu, botol dan perisa. Saat bahan baku dari supplier sudah tiba, Tempo Susu memulai produksi dengan pasteurisasi susu, pemberian perisa dan packaging susu ke dalam botol yang dilakukan pada satu hari. Selanjutnya produk susu disimpan satu hari sebelum dipindahkan ke dalam freezer selama satu hari agar produk tidak cepat rusak. Setelah melalui proses terbeut, produk siap dipasarkan ke retailer agar dapat dikonsumsi konsumen.

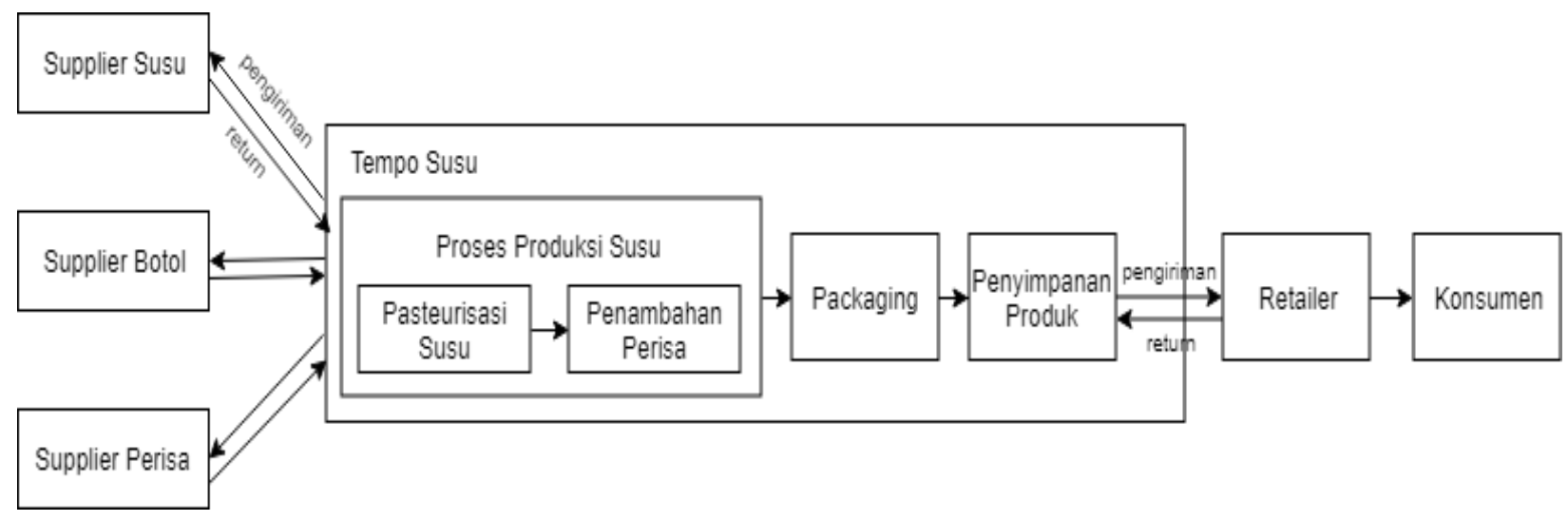

Gambar 1. Proses Bisnis dan Rantai Pasok Tempo Susu 


\subsection{Klasifikasi Pemetaan Rantai Pasok pada Model SCOR}

Berdasarkan proses bisnis dan rantai pasok Tempo Susu dilakukan pemetaan metrik level 3, 2 dan 1 sesuai dengan panduan SCOR. Pemetaan digambarkan dalam model hierarki pada Gambar 2. Penjabaran kode akan tertera pada Tabel 2.

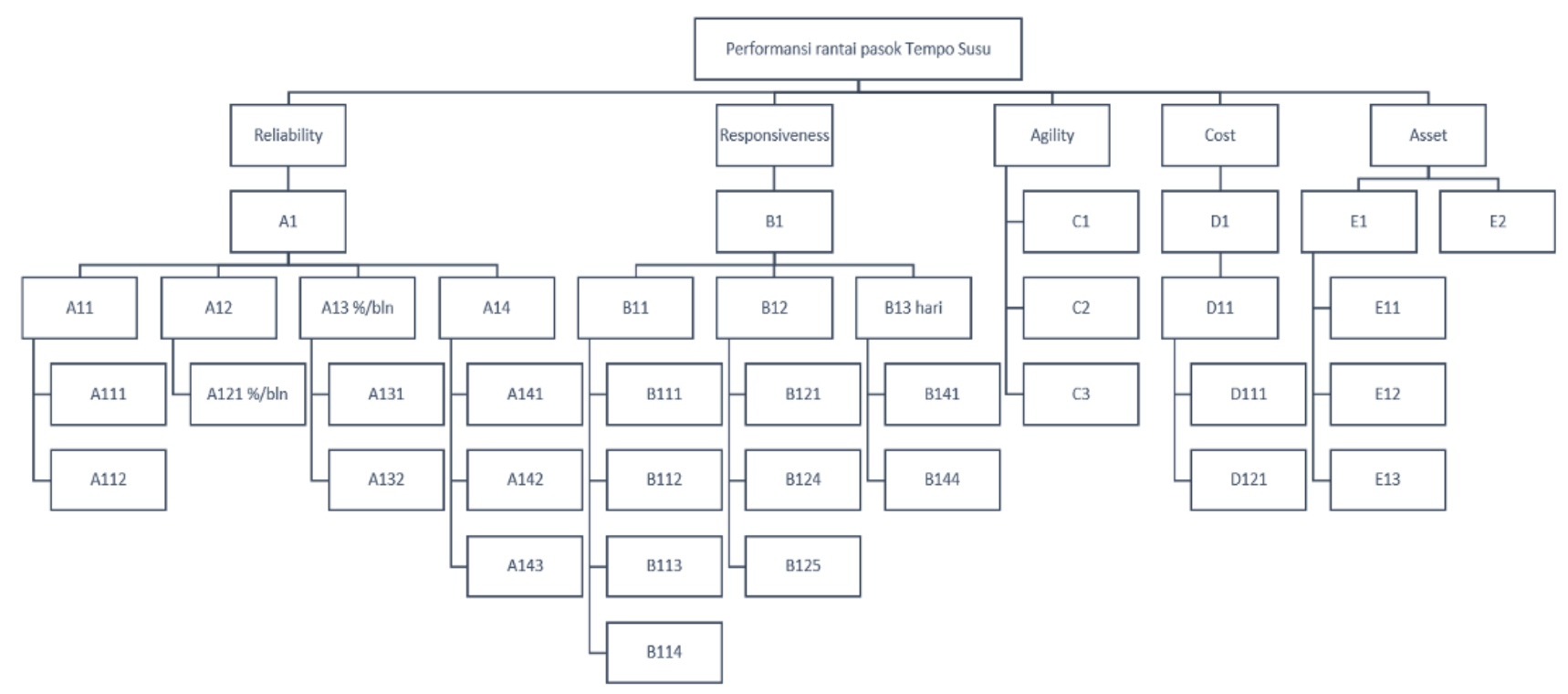

Gambar 2. Model Hierarki SCOR Rantai Pasok Tempo Susu

Tabel 2. Penjabaran Kode Metrik

\begin{tabular}{|c|c|c|c|}
\hline \multirow{2}{*}{$\begin{array}{l}\text { Performance } \\
\text { Attributes }\end{array}$} & \multicolumn{3}{|c|}{ Metrik SCOR } \\
\hline & Level 1 & Level 2 & Level 3 \\
\hline \multirow{8}{*}{ Reliability } & \multirow{8}{*}{$\begin{array}{l}\text { Perfect Order } \\
\text { Fulfillment }\end{array}$} & \multirow{2}{*}{$\%$ of orders delivered in full } & Delivery Item Accuracy \\
\hline & & & Delivery Quantity Accuracy \\
\hline & & $\begin{array}{l}\text { Delivery Performance to } \\
\text { Customer Commit Date }\end{array}$ & Delivery Location Accuracy \\
\hline & & \multirow{2}{*}{ Documentation Accuracy } & Payment Documentation Accuracy \\
\hline & & & Shipping Documentation Accuracy \\
\hline & & \multirow{3}{*}{ Perfect Condition } & \% Orders/Lines Received Damage Free \\
\hline & & & $\begin{array}{l}\text { Orders Delivered Damage Free } \\
\text { Conformance }\end{array}$ \\
\hline & & & Warranty and Returns \\
\hline \multirow{8}{*}{ Responsiveness } & \multirow{8}{*}{$\begin{array}{l}\text { Order } \\
\text { fulfillment } \\
\text { cycle time }\end{array}$} & \multirow{3}{*}{ Source cycle time } & Receive product cycle time \\
\hline & & & Select supplier and negotiate cycle time \\
\hline & & & Transfer product cycle time \\
\hline & & \multirow{3}{*}{ Make cycle time } & Produce and test cycle time \\
\hline & & & Release finished product to deliver cycle time \\
\hline & & & Package cycle time \\
\hline & & \multirow[t]{2}{*}{ Delivery cycle time } & $\begin{array}{l}\text { Receive product from source or make cycle } \\
\text { time }\end{array}$ \\
\hline & & & Ship product cycle time \\
\hline \multirow{3}{*}{ Agility } & $\begin{array}{l}\text { Upside } \\
\text { Supply Chain } \\
\text { Flexibility }\end{array}$ & \multirow{3}{*}{ - } & \\
\hline & $\begin{array}{l}\text { Upside } \\
\text { Supply Chain } \\
\text { Adaptability } \\
\end{array}$ & & \\
\hline & $\begin{array}{l}\text { Overall Value } \\
\text { at Risk (VAR) }\end{array}$ & & \\
\hline
\end{tabular}




\begin{tabular}{|l|l|l|l|}
\hline \multirow{2}{*}{ Cost } & $\begin{array}{l}\text { Total Cost to } \\
\text { Serve }\end{array}$ & Cost of Goods Sold & Direct material cost \\
\cline { 3 - 4 } & $\begin{array}{l}\text { Cash-to-cash } \\
\text { cycle time }\end{array}$ & Days sales outstanding & - \\
\cline { 2 - 4 } $\begin{array}{l}\text { Assets } \\
\text { Management }\end{array}$ & $\begin{array}{l}\text { Return on } \\
\text { Supply Chain } \\
\text { Fixed }\end{array}$ & - & - \\
\hline
\end{tabular}

Tabel 3. Hasil Normalisasi Metrik

\begin{tabular}{|c|l||c|c|c|c|}
\hline No & \multicolumn{1}{|c|}{ Metrik } & Terbaik & Aktual & Terburuk & Skor \\
\hline 1. & Perfect Order Fulfillment & $100 \%$ & $99,7 \%$ & $98,8 \%$ & 75 \\
\hline 2. & Order Fulfillment Cycle Time & 17 & 34 & 51 & 50 \\
\hline 3. & Upside Supply Chain Flexibility & 15 & 30 & 60 & 66,7 \\
\hline 4. & $\begin{array}{l}\text { Upside Supply Chain } \\
\text { Adaptability }\end{array}$ & $66,7 \%$ & $33,3 \%$ & $20 \%$ & 28,4 \\
\hline 5. & Overall Value at Risk(VAR) & 100000 & 112000 & 170000 & 82,9 \\
\hline 6. & Total Cost to Serve & 269000 & 276500 & 285000 & 53,1 \\
\hline 7. & Cash-to-Cash Cycle Time & 7 & 13 & 24 & 64,7 \\
\hline 8. & $\begin{array}{l}\text { Return on Supply Chain Fixed } \\
\text { Asset }\end{array}$ & 1,00423 & 1,00159 & 0,99859 & 53,2 \\
\hline
\end{tabular}

\subsection{Perhitungan Nilai Aktual Metrik}

Setelah mendapatkan data kuantitatif mengenai metrik-metrik yang telah dipetakan sebelumnya, dilakukan perhitungan nilai aktual metrik. Perhitungan dilakukan dilakukan berdasarkan buku panduan SCOR ver. 11 (Supply Chain Council, 2012).

\subsection{Normalisasi Nilai Aktual Metrik}

Hasil perhitungan metrik mempunyai skala yang berbeda. Agar skala ukuran menjadi sama perlu dilakukan penyeragaman skala dengan normalisasi. Peneliti melakukan normalisasi dengan menggunakan Pers. 1. Perlu diketahui kinerja aktual yang telah dihitung pada tahap sebelumnya (aktual) dan performa terbaik (max) serta performa terburuk (min), sehingga hasil normalisasi berupa skor didapatkan. Hasil normalisasi atau skor tertera pada Tabel 3.

\subsection{Pembobotan AHP}

Pembobotan AHP dilakukan dengan membandingkan antara kriteria dengan kriteria dan subkriteria dengan subkriteria. Kriteria disini merupakan proses rantai pasok (plan, make, sources, deliver, return). Hasil dari perhitungan pembanding kriteria akan menghasilkan bobot kriteria. Subkriteria pada pembobotan ini merupakan performance attributes (reliability, responsiveness, agility, cost, dan asset management). Hasil perhitungan pembanding subkriteria akan menghasilkan bobot subkriteria. Hasil pembobotan AHP didapat dari perkalian metriks antara bobot kriteria dengan bobot subkriteria. Tabel 4 menampilkan hasil pembobotan AHP berupa bobot.

Tabel 4. Hasil Pembobotan AHP

\begin{tabular}{|c|c|c|}
\hline No & Atribut Kinerja & Bobot \\
\hline 1 & Reliability & 0,14 \\
\hline 2 & Responsiveness & 0,15 \\
\hline 3 & Agility & 0,12 \\
\hline 4 & Cost & 0,23 \\
\hline 5 & Asset Management & 0,35 \\
\hline
\end{tabular}

\subsection{Perhitungan Nilai Akhir}

Nilai akhir didapatkan dari perkalian hasil normalisasi (skor) dan hasil pembobotan AHP (bobot). Melalui nilai akhir dapat ditentukan indikator kinerja Tempo Susu tergolong baik atau buruk serta mengetahui metrik performances attributesdan metrik yang paling baik serta buruk. Hasil perhitungan nilai akhir terdapat pada Tabel 5. 
Tabel 5. Hasil Nilai Akhir

\begin{tabular}{|c|c|c|c|c|c|c|}
\hline $\begin{array}{c}\text { Performance } \\
\text { Attributes }\end{array}$ & Metrik SCOR & $\begin{array}{l}\text { Nilai Normalisasi } \\
\text { Setiap Metrik }\end{array}$ & $\begin{array}{l}\text { Nilai Normalisasi } \\
\text { Setiap Performance } \\
\text { Attributes }\end{array}$ & Bobot & $\begin{array}{c}\text { Nilai Kinerja } \\
\text { setiap Metrik yang } \\
\text { dikali dengan } \\
\text { bobot } \\
\end{array}$ & $\begin{array}{c}\text { Nilai Kinerja } \\
\text { Setiap Atribut } \\
\text { yang dikali } \\
\text { dengan bobot } \\
\end{array}$ \\
\hline Reliability & $\begin{array}{c}\text { Perfect Order } \\
\text { Fulfillment }\end{array}$ & 75 & 75 & 0,14 & 10,5 & 10,5 \\
\hline $\begin{array}{l}\text { Responsive } \\
\text { ness }\end{array}$ & $\begin{array}{c}\text { Order } \\
\text { Fulfillment } \\
\text { Cycle Time }\end{array}$ & 50 & 50 & 0,15 & 7,5 & 7,5 \\
\hline \multirow{3}{*}{ Agility } & $\begin{array}{c}\text { Upside Supply } \\
\text { Chain } \\
\text { Flexibility }\end{array}$ & 66,7 & \multirow{3}{*}{59,3} & \multirow{3}{*}{0,12} & 8,67 & \multirow{3}{*}{7,71} \\
\hline & $\begin{array}{c}\text { Upside Supply } \\
\text { Chain } \\
\text { Adaptability }\end{array}$ & 28,4 & & & 3,69 & \\
\hline & $\begin{array}{l}\text { Overall Value } \\
\text { at Risk(VAR) }\end{array}$ & 82,9 & & & 10,8 & \\
\hline Cost & $\begin{array}{c}\text { Total Cost to } \\
\text { Serve }\end{array}$ & 53,1 & 53,1 & 0,23 & 12,21 & 12,21 \\
\hline \multirow{2}{*}{$\begin{array}{c}\text { Assets } \\
\text { Manageme } \\
n t\end{array}$} & $\begin{array}{c}\text { Cash-to-Cash } \\
\text { Cycle Time }\end{array}$ & 64,7 & \multirow[b]{2}{*}{58,95} & \multirow[b]{2}{*}{0,35} & 22,65 & \multirow[b]{2}{*}{20,63} \\
\hline & $\begin{array}{c}\text { Return on } \\
\text { Supply Chain } \\
\text { Fixed Asset }\end{array}$ & 53,2 & & & 18,62 & \\
\hline \multicolumn{6}{|c|}{ Nilai Akhir Kinerja Rantai Pasok } & 58,55 \\
\hline
\end{tabular}

\section{KESIMPULAN}

Berdasarkan hasil penelitian dengan menggunakan SCOR dan AHP, pengukuran performance attributes Tempo Susu menghasilkan nilai akhir yang sebesar 58,55, yaitu tergolong average. Nilai performances attributes reliability dan metriknya perfect order fulfillment sebesar 75 dengan nilai kinerja 10,5. Sedangkan nilai performances attributes responsiveness dan metriknya Order Fulfillment Cycle Time sebesar 50 dengan nilai kinerja 7,5. Hasil ini merupakan hasil terendah. Adapun nilai performances attributes agility sebesar 59,3. Metriknya Upside Supply Chain Flexibility sebesar 66,7, Upside Supply Chain Adaptability sebesar 28,4, Secara umum Value at Risk (VAR) sebesar 82,9 dengan nilai kinerja agility sebesar 7,71. Untuk nilai performances attributes cost dan metrik Total Cost to Serve sebesar 53,1 dengan nilai kinerja 12,21. Pada nilai performances attributes Assets Management sebesar 58,95. Metrik Cash-to-Cash Cycle Time sebesar 64,7 dan Return on Supply Chain Fixed Asset sebesar 53,2. Nilai kinerja Asset Management sebesar 20,63 sebagai hasil tertinggi.

\section{SARAN}

Tempo susu perlu meningkatkan kinerja pada performance attributes responsiveness yang mencakup proses Plan, Source, Make, Deliver, dan Return. Serta pada metrik Performance Attributes Upside Supply Chain Adaptability yang mencakup proses Make, Deliver, dan Return agar dapat meningkatkan produktivitas berupa kapasitas sehingga dapat melakukan ekspansi.

\section{DAFTAR PUSTAKA}

Budiman, V. E. 2013. Evaluasi Kinerja Supply Chain pada UD. Maju Jaya di Desa Tiwoho Kabupaten Minahasa Utara, J. Chem. Inf. Model., 53(9), 16891699.

Cangelosi, J. S. 2010. Definisi Pengukuran dan Penilaian Menurut Para Ahli. https://mahasiswaupiserang.wordpress.com/2010/0 9/27/definisi-pengukuran-dan-penilaian-menurutpara-ahli\%. (diakses tanggal 5 Oktober 2018)

Chopra, Sunil \& Meindl, Peter, 2016, Supply Chain Management: strategy, planning, and operation, $6^{\text {th }}$ ed, USA: Pearson Education, Inc.

Luthfiana, A. C. \& Perdana, Y. R. 2001. Pengukuran Performansi Supply Chain dengan Pendekatan Supply Chain Operation Reference (SCOR) dan Analytical Hierarchy Process (AHP) Studi Kasus: PT. Indofarma Global Medika. B.Eng Thesis. Department of Industry Engineering, UIN Sunan Kalijaga, Yogyakarta.

Moehriono, 2012, Pengukuran Kinerja Berbasis Kompetensi, Jakarta: Raja Grafindo Persada. 
Muhammad, A. \& Yuslidar, C. E. 2012. Evaluasi Pengelolaan Kinerja Rantai Pasok dengan Pendekatan SCOR Model pada Swalayan Asiamart Lhokseumawe, Ind. Eng. J., 1(1), pp. 44-51.

Mutakin, A. \& Hubeis, M. 2011. Pengukuran Kinerja Manajemen Rantai Pasokan dengan SCOR Model 9.0 (Studi Kasus di PT Indocement Tunggal Prakarsa, Tbk), J. Manaj. dan Organ., II(3), 89103.

Natalia, C. \& R. Astuario, R. 2015. Penerapan Model Green SCOR untuk Pengukuran Kinerja Green Supply Chain, J. Metris, 16, 97-106.

Palupi, S., Lailiyah, S., \& Sihotang, V. 2014. Sistem Pendukung Keputusan Pemerimaan Karyawan pada PT. Suryaintan Tri Lestari dengan Metode Ahp Berbasis Web. Sebatik, 11(1), 25-31.

Pranoto, Y. A., Muslim, M. A., \& Hasanah, N. 2013. Rancang Bangun dan Analisis Decision Support System Menggunakan Metode Analythical Hierarchy Process untuk Penilaian Kinerja Karyawan, Prosiding EECCIS, 7(1), 91-96.

Setiawan, A., Marimin, Arkeman, Y., \& Udin, F. 2010. Integrasi Model SCOR dan Fuzzy AHP untuk
Perancangan Metrik Pengukuran Kinerja Rantai Pasok Sayuran,” J. Manaj. dan Organ., I(3), 148161.

Supply Chain Council, 2012, Supply Chain Operation Reference Model, $11^{\text {th }}$ ed, USA: Supply Chain Council, Inc.

Ukkas, M. I., Yusnita, A., \& Wandana, E. 2013. Sistem Pendukung Keputusan Kelayakan Pemberian Kredit Menggunakan Metode AHP Pada Bank Danamon Cabang Segiri Samarinda, Sebatik, 10(1), 22-28.

Wahyuniardi, R. \& Pasundan, U. 2017. Pengukuran Kinerja Supply Chain dengan Pendekatan Supply Chain Operation Reference (SCOR), J. Ilm. Tek. Ind., vol. 16(2), 123-132.

Wigaringtyas, L. D. 2013. Pengukuran Kinerja Supply Chain Management dengan Pendekatan Supply Chain Operation Reference (SCOR) (Studi Kasus: UKM Batik Sekar Arum, Pajang, Surakarta). B.Eng. Thesis. Faculty of Engineering, Universitas Muhammadiyah Surakarta. 